\title{
Editorial
}

Neuro

epidemiology

\section{What the COVID-19 Crisis Is Telling Humanity}

\author{
David O. Wiebers ${ }^{\mathrm{a}} \quad$ Valery L. Feigin ${ }^{\mathrm{b}}$ \\ ${ }^{a}$ Emeritus Professor of Neurology, Consultant Emeritus, Departments of Neurology and Health Sciences Research, \\ Mayo Clinic and Mayo Foundation, Rochester, MN, USA; ${ }^{b}$ National Institute for Stroke and Applied Neurosciences, \\ Faculty of Health and Environmental Studies, Auckland University of Technology, Auckland, New Zealand
}

The world is enveloped in a global health emergency that is exacting enormous medical and economic tolls upon humanity. The SARS-CoV-2 that has caused the current COVID-19 pandemic is thought to have originated in bats and, via an intermediary such as the pangolin, to have found its way from a "wet market" where live wildlife species were being sold for human consumption in Wuhan, China, to one or more humans at that location [1]. Within months, this highly infectious virus spread throughout China and around the world, currently involving at least 185 countries and territories, with a trail of incredible damage in its wake [2]. The medical community finds itself on the front lines throughout the world dealing with the immediate human health consequences of this rapidly evolving crisis and trying to develop therapies and vaccines, as countries and their leaders attempt to mitigate the overwhelming societal and economic devastations that are unfolding.

From a neuropsychiatric perspective, there are obvious signs of global psychological distress related to social isolation and fears of illness, death, and countless uncertainties about the future [3]. Less attention has been given to neurological manifestations including headache, anosmia, ageusia, ataxia, paresthesia, ischemic stroke, seizures, and various encephalopathies, collectively occurring in up to nearly $40 \%$ of hospitalized COVID-19 patients in early series. Encephalopathies have been more

\section{KARGER}

() 2020 S. Karger AG, Basel

karger@karger.com

www.karger.com/ned likely to occur in severely ill patients and have included at least one case of documented viral encephalitis with SARS-CoV-2 in the cerebrospinal fluid [4].

Past respiratory viral pandemics have been associated with other delayed neurological sequelae, including acute inflammatory polyradiculopathy, peripheral neuropathy, myopathy, brainstem encephalitis, and Parkinsonism, the latter of which was prominently associated with the so-called Spanish influenza pandemic of 1918 [5]. Given the immense global burden of COVID-19, it is likely that the long-term neuropsychiatric complications will be substantial and it will be important for the medical community to prospectively monitor patients to establish the nature and extent of such morbidities while also dealing with the acute manifestations of this illness that are unfolding each day in emergency rooms throughout the world $[3,5]$.

Yet, in the midst of all of the pandemonium and destruction, and as we begin to find our way through this crisis, it is imperative for us as a society and species to focus and reflect deeply upon what this and other related human health crises are telling us about our role in these increasingly frequent events and about what we can do to avoid them in the future. Failure to do so may result in the unwitting extermination of all or a good part of our species from this planet. Although it is tempting for us to lay the blame for pandemics such as COVID-19 on bats, 
pangolins, or other wild species, it is human behavior that is responsible for the vast majority of zoonotic diseases that jump the species barrier from animals to humans.

The US Centers for Disease Control and Prevention (CDC) observes that "...3 in every 4 new or emerging infectious diseases in people come from animals." These infections are caused not only by viruses but also by bacteria, fungi, and parasites from a variety of animal sources [6]. The alarming increase in frequency of these lethal zoonotic diseases relates in large part to our human-dominated ecosystem with increasingly unnatural human-animal close contact, grossly aberrant crowding of animals for human purposes, destruction of animal habitats, and vast numbers of highly mobile humans to swiftly carry these diseases throughout the world [7].

As is likely with COVID-19, the outbreak of SARS (an earlier severe acute respiratory syndrome) in 2003 was the result of a coronavirus that originated in bats with subsequent infection of wild animals sold in live-animal street markets in China. Such markets provide breeding grounds for these and countless other zoonotic pathogens with sick, highly stressed, and overcrowded animals in highly unsanitary conditions. The opportunity for human transfer of these pathogens is increased immensely by allowing direct access to large crowds of humans [8].

The human immunodeficiency virus (HIV), which has infected 75 million people and killed 32 million since the onset of acquired immunodeficiency syndrome (AIDS) in the 1980s, originated in a type of chimpanzee in Central Africa. Scientists have generally concluded that the chimpanzee version of the virus (called simian immunodeficiency virus) was transmitted to humans and mutated into HIV when humans hunted these chimpanzees for meat and came into contact with their infected blood [9].

The hunting, capturing, and selling of wild animals for human consumption, particularly in connection with live-animal markets, clearly constitute major public health risks. Continuing these practices will assure further human health crises with potentially even greater destructive power in the future.

Another well-recognized source for increasingly lethal human zoonoses is the massive overcrowding of animals for human consumption in industrial "factory farm" environments - also known as concentrated animal feeding operations.

Over the last 40 years, as the factory farm model has become a global phenomenon, a host of avian influenza (bird flu) viruses, including $\mathrm{H} 5 \mathrm{~N} 1$, have emerged in countries with large-scale industrial poultry operations $[10,11]$. Intensive confinement of unprecedented num- bers of chickens in these facilities to lower cost has provided a fertile ground for the development of an everincreasing supply of new pathogens. And while bird flu was once a very rare disease among chickens, today we see outbreaks occurring every year [12]. Transmission of these diseases from chickens to humans was almost nonexistent 25 years ago; now serious outbreaks are occurring regularly - more in the past 15 years than in the entire 20 th century [11].

Initially detected in humans in 2009 , the $\mathrm{H} 1 \mathrm{~N} 1$ pandemic (the so-called swine flu because of its origin in pigs) constituted the 1st worldwide flu pandemic in 40 years. The CDC estimates that over the past 10 years, this disease has killed between 151,700 and 575,400 people worldwide. Pigs had long been considered a possible mixing vessel for influenza viruses that originated within pigs, birds, and humans, and the CDC has concluded that this virus resulted from reassortment, a process through which two or more influenza viruses can swap genetic information by infecting a single human or animal host [13]. Larger numbers of pigs in closer proximity provide greater opportunities for this to occur, and the mixing of live pigs from North America and Eurasia through international trade or other means could have also contributed to the circumstances necessary for this reassortment to occur [14].

The large-scale confinement of animals for human consumption has also played a major direct role in another ongoing health crisis in the USA and around the world - antibiotic resistance. Nearly $80 \%$ of the antibiotics sold in the USA are now used for livestock feed to prevent disease and promote growth [15]. Intensive confinement operations require more antibiotics than family farms, and if the bacteria that naturally exist in these animals acquire antibiotic resistance genes, treatment becomes ineffective. This circumstance constitutes a threat not only to animal health but also to human health [16].

Humans may be exposed to antibiotic-resistant organisms by handling or eating raw or undercooked meat, coming into contact with farm animals or their feces, and/ or eating produce or consuming water (including recreational water) that has come into contact with animal feces [17]. Robust scientific data confirm that proximity to livestock operations and manure application to crop fields are each associated with the likelihood of acquiring antibiotic-resistant infections in humans [18]. Researchers at the Johns Hopkins Bloomberg School of Public Health drove cars, windows down, behind trucks that were transporting broiler chickens from farms to slaughterhouses in Virginia and Maryland; they documented 
antibiotic-resistant bacteria in the air inside the cars, as well as on the top of soda cans in the cars' cupholders [19]. Antibiotic-resistant infections constitute a major and growing global health threat and now kill an estimated 35,000 people in the USA and 700,000 people worldwide per year [20].

One further fundamental source for the increasing threat of pandemics and other human health crises is habitat destruction. Vast numbers of wildlife species are threatened with extinction from cutting down forests and expanding urban areas and industrial activities. The survivors are forced into closer proximity to themselves and humans, increasing the likelihood of transforming what would otherwise be benign animal microbes into deadly human pathogens. To compound the issue, much of the land that is being lost to deforestation is being converted to land for raising more animals for human consumption [7].

Our species has come to the edge of the cliff on these issues, and the COVID-19 pandemic is forcing us to make a choice between either changing our thinking and practices in these realms, or facing increasing destruction and perhaps self-annihilation. Medical experts are painfully aware of the undeniable hazards of continuing along our current trajectory. Dr. Amesh Adalja of the Johns Hopkins Center for Health Security writes openly of the relatively new avian influenza, H7N9, that has been considered one of the most concerning of all pandemic threats over the past few years. Although an epidemic of H7N9 began in southern China in 2013, there has to date been no sustained human-to-human transmission. Nevertheless, more than 1,500 human cases have occurred with a case fatality rate of $40 \%$, and Adalja warns that "If H7N9 achieves sustained human-to-human transmission, it would arguably be the worst health and national security threat faced by the world in literally a century. An H7N9 pandemic could well be worse - perhaps much worse than the great pandemic of 1918" [21] that killed an estimated 50 million people [22].

Rather than simply attempting to react to crises like COVID-19 after death and destruction are already upon us, we need to have the vision, wisdom, and compassion to address fundamental underlying causes and act now to mitigate and prevent the numerous disasters that are literally waiting to happen. The Chinese government should be applauded for taking the much-needed step of banning the trade and consumption of wild animals in China on February 24, 2020. Although shutting down this USD74 billion wildlife farming industry has been decried by some as economically harmful, such harm pales over- whelmingly in comparison to the vast health and economic threats to China and the world involved in continuing to allow business as usual. Other nations throughout the world should also prohibit such practices, particularly in association with live-animal markets.

Intensive confinement of animals in factory farm operations should be discontinued worldwide for the sake of animals, humans, and the environment, and we should rapidly evolve to eating other forms of protein that are safer for humans, including plant-based meat alternatives and cultured meat (produced by culturing animal cells). Additional investment in plant-based agriculture to grow crops to feed humans rather than livestock for human consumption would feed more people while utilizing far less land and water, allowing for the preservation of vital ecosystems for innumerable species.

The time has come for us to rethink our relationship with all life on this planet - other humans, nonhumans, and the earth, a life form in itself. What is good for nonhumans and the earth is virtually always in the best interests of humans, given the profound interconnectedness of all life. All that we do depends upon abundant plant and animal life as well as clean air and water. Each of us can have a positive impact upon these fundamentals by demonstrating and inspiring an enhanced mindfulness, beginning most basically with what we eat and how all of our daily choices and actions may be affecting animals and natural habitats. Ultimately, the survival, not only of other life forms on this planet, but also of our own, will depend upon humanity's ability to recognize the oneness of all that exists and the importance and deeper significance of compassion for all life.

\section{Disclosure Statement}

The authors have no conflicts of interest to disclose.

References

1 Morens DM, Daszak P, Taubenberger JK. Escaping Pandora's box: another novel coronavirus. N Engl J Med. 2020;382(14):1293-5.

2 Johns Hopkins Coronavirus Resource Center ; 2020. Available from https://coronavirus. jhu.edu/map.html.

3 Troyer EA, Kohn JN, Hong S. Are we facing a crashing wave of neuropsychiatric sequelae of COVID-19? Neuropsychiatric symptoms and potential immunologic mechanisms. Brain Behav Immun. 2020.

4 Xiang P, Xu XM, Gao LL, Wang HZ, Xiong HF, Li RH. First case of 2019 novel coronavirus disease with encephalitis. ChinaXiv. 2020; T202003.00015. 
5 Wu Y, Xu X, Chen Z, Duan J, Hashimoto K, Yang L, et al. Nervous system involvement after infection with COVID-19 and other coronaviruses. Brain Behav Immun. 2020.

6 Centers for Disease Control and Prevention; 2020. Available from https://www.cdc.gov/ onehealth/basics/zoonotic-diseases.html.

7 Allen T, Murray KA, Zambrana-Torrelio C, Morse SS, Rondinini C, Di Marco M, et al. Global hotspots and correlates of emerging zoonotic diseases. Nat Commun. 2017;8(1): 1124.

8 Cui J, Li F, Shi ZL. Origin and evolution of pathogenic coronaviruses. Nat Rev Microbiol. 2019;17(3):181-92.

9 Sharp PM, Shaw GM, Hahn BH. Simian immunodeficiency virus infection of chimpanzees. J Virol. 2005;79(7):3891-902.

10 Shortridge KF, Peiris JS, Guan Y. The next influenza pandemic: lessons from Hong Kong. J Appl Microbiol. 2003;94(Suppl 1):70S-9S.

11 Gregor M. Bird flu: a virus of our own hatching. New York, NY. Lantern Books; 2006.

12 Capua I, Alexander DJ. Avian influenza: recent developments. Avian Pathol. 2004; 33(4):393-404.
13 Centers for Disease Control and Prevention; 2020. Available from https://www.cdc.gov/ flu/pandemic-resources/2009-h1n1-pandemic.html.

14 Mena I, Nelson MI, Quezada-Monroy F, Dutta J, Cortes-Fernández R, Lara-Puente JH, et al. Origins of the 2009 H1N1 influenza pandemic in swine in Mexico. Elife. 2016;5(5): e16777.

15 Martin MJ, Thottathil SE, Newman TB. Antibiotics overuse in animal agriculture: a call to action for health care providers. Am J Public Health. 2015;105(12):2409-10.

16 Silbergeld EK, Graham J, Price LB. Industrial food animal production, antimicrobial resistance, and human health. Annu Rev Public Health. 2008;29:151-69.

17 Centers for Disease Control and Prevention; 2020. Available from https://www.cdc.gov/ foodsafety/challenges/antibiotic-resistance. html.
18 Casey JA, Curriero FC, Cosgrove SE, Nachman KE, Schwartz BS. High-density livestock operations, crop field application of manure, and risk of community-associated methicillin-resistant staphylococcus aureus infection in Pennsylvania. JAMA Intern Med. 2013; 173(21):1980-90.

19 Rule AM, Evans SL, Silbergeld EK. Food animal transport: a potential source of community exposures to health hazards from industrial farming (CAFOs). J Infect Public Health. 2008;1(1):33-9.

20 O'neill J. Tackling drug-resistant infections globally: final report and recommendations; 2016. Available from https://amr-review.org/ sites/default/files/160525_Finalpaper_withcover.pdf.

21 Adalja AA. The ascent of H7N9. Johns Hopkins School of Public Health Center for Health Security Clinicians Biosecurity Report; 2017. Available from www.centerforhealthsecurity. org/cbn/2017/cbnreport_10012017.html.

22 Morens DM, Folkers GK, Fauci AS. The challenge of emerging and re-emerging infectious diseases. Nature. 2004;430(6996):242-9. 